\title{
Raoultella planticola
}

National Cancer Institute

\section{Source}

National Cancer Institute. Raoultella planticola. NCI Thesaurus. Code C86716.

A species of Gram negative, rod shaped bacteria assigned to the phylum Proteobacteria.

This species can deaminate tryptophan, is able to grow at 10 degrees Celsius and uses

sorbose as a carbon source. R. planticola is a pathogen that can cause pancreatitis. 